\title{
Prospects for the development of the Russian system of agricultural consulting under the conditions of the digital transformation of agrarian economy
}

\author{
Maxim Osovin and Marina Kadomtseva* \\ Institute of Agrarian Problems of the Russian Academy of Sciences, 410012 Saratov, Russia
}

\begin{abstract}
In terms of macroeconomic and geopolitical instability, in order to increase the competitiveness of agro-food complex of the Russian Federation in world food markets, a scientifically based choice of institutional solutions is required to increase innovative activity in the agricultural sector and to ensure the transfer of technologies used in industries related to agriculture. A generalization of Russian and foreign practice of agricultural consulting showed that at the present stage of economic development, this institution should be considered as a center for the innovation spread, stimulating agricultural producers to constant increasing of their competencies in high technology. The comparison of the obtained and expected economic effect of the innovative activities of regional agricultural advisory services revealed that a flexible policy of budget co-financing contributes to an increase in the quality of services, and in the professionalism of consultants and their communication skills. It is concluded that the promising tasks of the Russian agricultural consulting system are the selection of optimal options for technical and technological support of production for small and medium-sized businesses; formation of packages of orders for the most popular applied research; popularization of precision and organic farming methods; participation in the development and implementation of sustainable rural development programs.
\end{abstract}

\section{Introduction}

In the context of the turn from the traditional to the "digital" model of the development of the agro-food complex, the growth dynamics of its production potential directly depends on the effectiveness of the mechanisms for the dissemination of agricultural knowledge among producers and on the introduction of the most promising scientific and technical developments in all segments of the production cycle. This process is impossible without a centralized agricultural consulting system for rural producers, but the procedure for completing the portfolio of proposals of information and consulting services (ICS) does not fully satisfy customers' expectations, which is largely the reason for the lack of demand for consulting services among representatives of the real sector of the economy. The changed socio-economic conditions came into conflict with the outdated concept of modernization of the agricultural production management system, which requires changes in consulting practice.

The agro-food complex of Russia and its basic industry, agriculture, are the leading system-forming spheres of the country's economy, which form the agrofood market, food and economic security, labour and settlement potential of rural territories. The process of the turn of the agro-food complex to the digital economy and informatization of rural territories of the Russian
Federation are regulated by the Federal Law of December 29, 2006 No. 264-FZ "On the Development of Agriculture", in which the provision of advisory assistance to agricultural producers is specified as one of the main directions of state support in the field of agriculture.

It is beyond argument that the part of ICS functions is gradually moving to the Internet space, and in a number of developed countries they are increasingly refusing to divide this system into federal and regional consulting services in favour of commercial consulting that works according to individual customer schemes, however, increased competition, internationalization and globalization of business stimulate the search of additional resources to improve production efficiency.

According to the forecast of the Ministry of Agriculture of the Russian Federation, by 2030 the popularity of information and consulting services around the world will increase by more than 2 times due to an increase in interest in remotely informing about the state of farmland and providing access for agricultural producers to specialized online services. In order not to miss opportunities and avoid the catch-up scenario of development in which patented platform technologies are purchased from Western companies, the outdated functions of ICS should be replaced by new ones related, first of all, to dissemination among interested consumers

Corresponding author: kozyreva_marina_@mail.ru 
of innovative developments, high-tech novelties and information products.

\section{Methods of research}

The theoretical and methodological basis of the study was the work of Russian and foreign scientists in the field of organization and development of the agricultural consulting system (J. Ingram [1], L. Klerkx [2], Yu.I. Klimenko, V.V.Lazovsky, G. Faure, Y. Desjeux, P. Gasselin [3]). The study of O. Muellerij, G.M. Demishkevich [4], I.S. Sandu, V.G. Savenko, M.Ya. Veselovsky, R. Ramos-Sandoval, F. Mas-Verdú and others [5] is devoted to the substantiation of the role of ICS in agricultural production and its innovative development. The characteristic of the classical and innovative functions of information and consulting services is presented in the works of C. Laurent, M. Cerf, P. Labarthe [6].

Some elements of the analysis of new styles and methods of ICS functioning, occurring under the influence of institutional transformations in the socioeconomic space, are reflected in the works of L. Madureira [7], R. Birner, K. Davis, J. Pender [8] and others. An assessment of qualitative changes in the practice of the farm sector advising is given in the studies of R. Nettle, A. Crawford, P. Brightling [9], N.G. Röling and M.A.E. Wagemakers [10].

The information base of the study was the data of the Ministry of Agriculture of the Russian Federation, reporting materials of the Federal Center for Agricultural Consulting and Retraining of Personnel of the Agroindustrial Complex, as well as the reports on the work of the regional information and consulting services of the agro-industrial complex. To compare Russian and foreign experience and assess the quality development of the national agricultural consultation system, the following results were used: "Agricultural Knowledge and Information System (AKIS)" (Farm Knowledge and Information Systems), "Farm Advisory System (FAS)" (National Farm Advisory System) drawn up at the request of the European Commission.

In the process of research, methods of systemic, comparative and factor analysis were applied.

\section{Results of research}

In 2018, the concept of the formation of information and consulting services to support agricultural producers was put into practice in 60 constituent entities of the Russian Federation, the total number of regional-level consulting centers amounted to 105 units, that was $51 \%$ higher than in 2006. The number of district-level ICS was 480 (up $35 \%$ compared with a year earlier). This positive dynamics is explained by the growing interest in ICS from farmers' associations and organizations located in the Volga, Siberian, North Caucasian and Far Eastern districts (fig.1).

For all the variety of forms of organization of information and consulting support for economic entities of the agro-food complex, the majority of the Russian agro-consulting services are structural units of sectoral management bodies, or, in rare cases, they are created on the basis of large regional multidisciplinary universities. This form is often sharply criticized by users, because it is considered insufficiently flexible and poorly adapted to changes in the external environment.

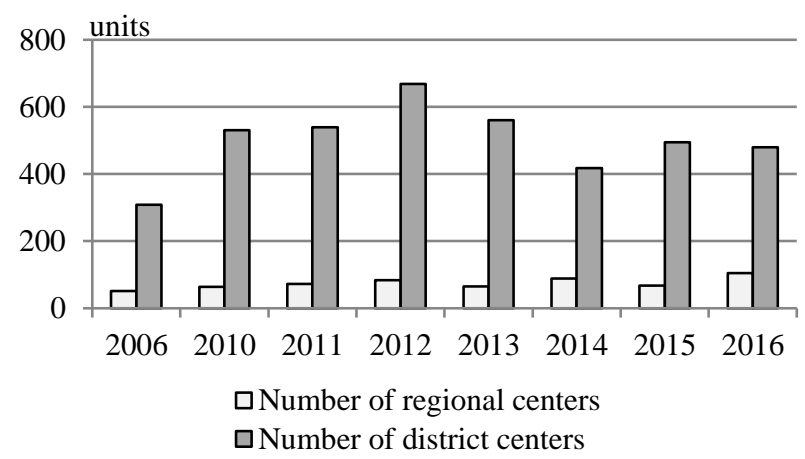

Fig. 1. Development of regional and district agricultural consulting organizations in 2006-2016, units

For comparison, nowadays there are about 2,900 extension service centers, 91 experimental stations for testing technologies, and only 10 agricultural research institutes in the United States. Last year, the extension service unit at the University Of Arkansas University Department Of Agriculture hosted 3.3 thousand exhibits, and out of 43 thousand state farmers, 21.6 thousand people turned to consultants, that is, approximately every second agricultural producer is the client of the service [11].

In most countries of the European Union, agricultural consulting services are mainly provided by commercial organizations, but the flexible policy of budget cofinancing of consulting services gives an opportunity to distribute responsibilities between farms and these organizations. In Germany, the share of government subsidizing for contracts for commercial consulting services is $60 \%$, and the share of expenses of farmers does not exceed $0.81 \%$ of total profit. In Belgium, Italy, Lithuania and Hungary, the state compensates about $80 \%$ of agricultural producers 'expenses for ICS services, and consumers' own expenses range from 2.19 to $0.8 \%$ of the annual income [12].

Analysis and comparison of the results of the research projects "Evaluation of the Implementation of the Farm Advisory System" and "Prospects for Farmers' Support: Advisory Services in European AKIS" [13], published by the European Commission, shows that in recent years more and more services in the EU countries related to the search for additional sources of increasing production efficiency through the use of resource-saving technologies are in great demand. They include renewable energy sources ( $40.1 \%$ of requests), ecology and environmental protection $(33.1 \%)$, diversification of production $(27.8 \%)$. Such a request structure is fully consistent with the concept of strategic development management for the long term period (fig. 2).

Functionally, Russian regional-level consulting centers provide individual or group services to customers within their competence: conduct field research, training 
events, seminars, exhibitions and specialized conferences. According to the annual monitoring of the provision of advisory assistance to agricultural producers and the rural population of the Russian Federation, in 2016356 demonstration facilities were organized (104 regional, 93 regional and 159 under agreements with agricultural organizations), 407 exhibitions (187 regional and 220 regional level) and 315 "Field Days" were held.

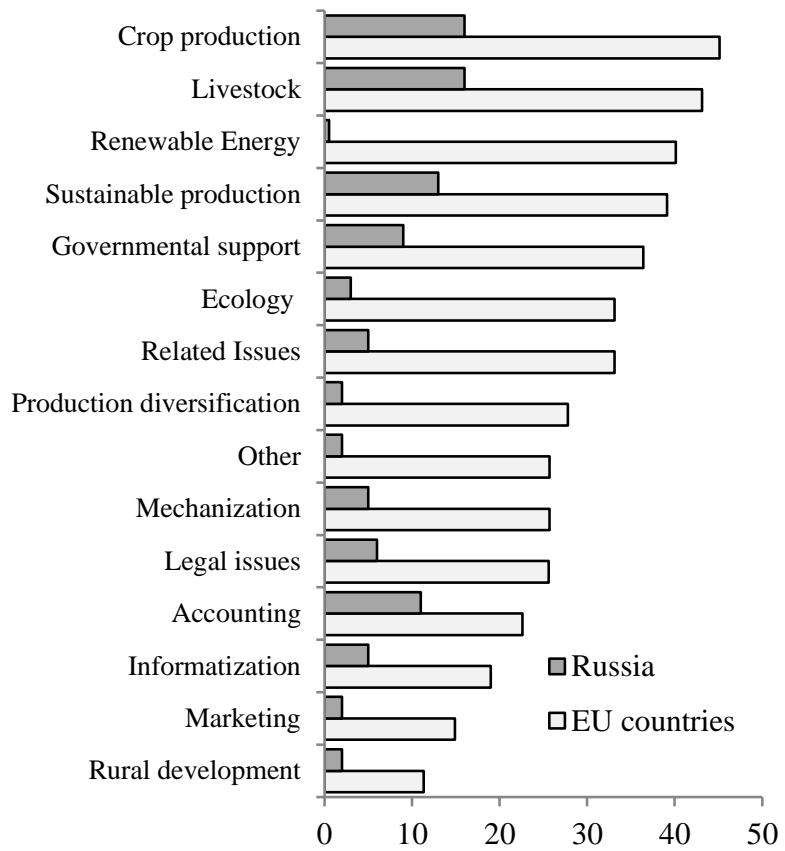

Fig. 2. Structure of consulting services provided by organizations of agricultural counseling in 2016, in (\%)

In 2016, ICS employees provided about 42 thousand consultations related to the state support. It included not only targeted information sharing about changes in industry legislation, but also specific assistance in preparing the necessary documentation for subsidies, providing direct communication and feedback between the heads of agricultural enterprises and regional authorities.

The analysis of the dynamics of demand for consulting services shows that compared with 2002, in 2016, the scope of interests of ICS clients has changed significantly. Although the provision of professional assistance in the field of crop production and animal husbandry is still in stable demand, the share of marketing advice has fallen from 10 to $2 \%$, mechanization advice - from 9 to $5 \%$, land relations from 5 to $1 \%$. On the other hand, answers to questions related to software and informatization have become more in demand (growth from 0.3 to $5 \%$ ).

A positive growth trend in the number of consultancy services was noted in the field of economy and organization of production (from 9 to $13 \%$ ), accounting (from 8 to $11 \%$ ), social development of the village (from 0.7 to $2 \%$ ) and legal support (from 5 to $6 \%$ ). Thus, ICS clients are now more selective about information sources and are striving to independently apply new knowledge in business planning and production design.
The analysis revealed a tendency to change the structure of users of information and consultation centers. Compared to 2012, the share of peasant (farmer) households in the ICS client base increased from 31 to $45 \%$, while the number of requests from large agricultural organizations decreased from 31 to $23 \%$, and their share became comparable with small forms of management (personal subsidiary plots, gardeners). From the author's point of view, the dimension factor is increasingly affecting the activity of ICS. Large enterprises have sufficient funding and are able to provide long-term strategic support for their own innovation policies (fig. 3).

Due to the functional and technological integrity of the production chain, agricultural holdings are one of the most investment-attractive forms of business in the Russian agro-industrial complex, providing it with an inflow of capital from both banking and industrial structures. At the same time, the dominant position of large agribusiness does not reduce the importance of medium and small-sized enterprises. Their competitive advantage is in flexibility, mobility, quick adaptation to external conditions, as well as in high speed of funds turnover and low management costs. Compared to enterprises of large legal form, they are most closely associated with local markets, covering almost all spheres of production of goods and services at the regional and municipal levels [14].

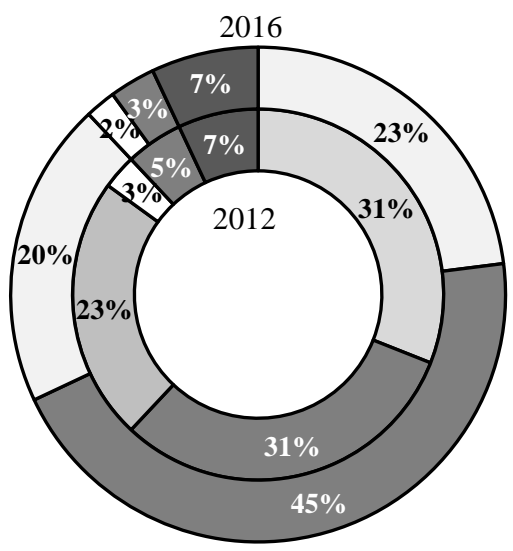

$$
\begin{aligned}
& \text { Agricultural organizations } \\
& \square \text { Peasant farms } \\
& \square \text { private farming } \\
& \square \text { Consumer cooperatives } \\
& \square \text { Processing and other enterprises } \\
& \text { Organizations of the agri-food complex management }
\end{aligned}
$$

Fig. 3. Structure of users of consulting services of agricultural consulting organizations for 2012 and 2016

Studying the experience of the most effective information and consulting services of the Russian regions shows that the implementation of the proposals of ICS specialists can many times reduce the risks of making wrong management decisions and ensure the sustainability of the enterprise. Regular informing on the correlation of demand, supply and related prices for food products provides an opportunity at the planning stage not only to rationally distribute the totality of the technical, labour and material and energy resources 
necessary to achieve the goals, but also to correctly correlate the organization's position with respect to its main competitors (table 1).

According to the monitoring of the provision of advisory assistance, in 2016, about 20 thousand agricultural organizations introduced more than 300 innovations in the field of organizing production, crop production and livestock production, and out of 240 individually designed investment and innovation projects, one out of two was mastered.

Table 1. Number of innovations implemented with the help of information and consulting services received from the implementation of the economic effect in 2011-2016

\begin{tabular}{|l|c|c|c|c|c|c|}
\hline & 2011 & 2012 & 2013 & 2014 & 2015 & 2016 \\
\hline $\begin{array}{l}\text { Innovation } \\
\text { introduced, units }\end{array}$ & 1311 & 2831 & 909 & 1445 & 570 & 534 \\
\hline $\begin{array}{l}\text { Economic effect, } \\
\text { million rubles }\end{array}$ & - & 198.4 & 391.9 & 1230 & 106.8 & 624.2 \\
\hline
\end{tabular}

Analyzing the results of the innovation activity of information and consulting services by service recipients, we can conclude that out of 324 owners of private farms who applied to ICS, 65 persons introduced recommended innovative solutions, but the lead-time percentage was 80 points (out of 221 projects proposed by ICS employees, 178 were implemented). This service turned out to be the most popular among peasant (farmer) households (86 households, lead-time percentage is 40 points) (table 2 ).

Table 2. Results of innovation activities of the Russian information and consulting services of the agro-industrial complex in 2016

\begin{tabular}{|c|c|c|c|c|c|c|c|c|}
\hline & \multicolumn{2}{|c|}{ 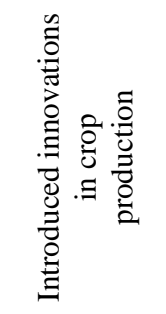 } & \multicolumn{2}{|c|}{ 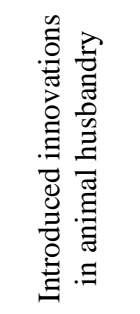 } & \multicolumn{2}{|c|}{ 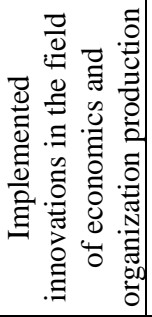 } & \multicolumn{2}{|c|}{ 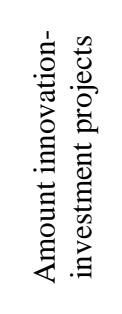 } \\
\hline & $\stackrel{\mathscr{a}}{\Xi}$ & 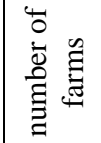 & $\stackrel{\mathscr{G}}{\Xi}$ & 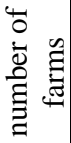 & $\stackrel{\mathscr{\Xi}}{\Xi}$ & 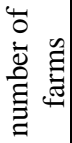 & $\begin{array}{l}\vec{d} \\
\frac{0}{0} \\
\frac{0}{0} \\
\frac{0}{0}\end{array}$ & 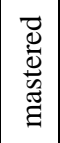 \\
\hline \begin{tabular}{|c|} 
Agricultural \\
organizations
\end{tabular} & 119 & 17633 & 139 & 116 & 47 & 35 & 240 & 121 \\
\hline Peasant farms & 52 & 78 & 58 & 56 & 28 & 24 & 251 & 112 \\
\hline $\begin{array}{l}\text { Personal utility } \\
\text { farms }\end{array}$ & 23 & 260 & 30 & 59 & 12 & 36 & 178 & 26 \\
\hline Others & 2 & - & 20 & - & 4 & - & 26 & - \\
\hline
\end{tabular}

In 2016, the total economic effect from the innovative activities of regional agricultural consulting services amounted to 624.2 million rubbles with the expected level of 1211.0 million rubbles $(51.5 \%)$. The most popular were consultations in the field of crop production. According to the recommendations of ICS employees, 194 innovative solutions were introduced in this industry, and they brought an income of 221 million rubbles ( $91 \%$ of the planned) (table 3 ).

In the field of animal husbandry, the efficiency of ICS is not so high. Although the implementation of 227 projects allowed receiving 371 million rubbles, but this indicator is almost three times less than planned. Compared to crop production, this industry is considered to be more risky for innovative design.

Table 3. The effectiveness of the introduction of innovations introduced through the information and consulting services

\begin{tabular}{|c|c|c|}
\hline & $\begin{array}{c}\text { Expected economic } \\
\text { effect, } \\
\text { thousand rubles }\end{array}$ & $\begin{array}{c}\text { The resulting } \\
\text { economic effect, } \\
\text { thousand rubles }\end{array}$ \\
\hline $\begin{array}{c}\text { Innovations in crop } \\
\text { production }\end{array}$ & 243701 & 221944 \\
\hline Livestock Innovation & 906946 & 371917 \\
\hline $\begin{array}{c}\text { Innovations in } \\
\text { economics and } \\
\text { production organization }\end{array}$ & 60870 & 30371.1 \\
\hline
\end{tabular}

It should be noted that a characteristic feature of the Russian agro-food complex is the predominance of small forms of management in its structure. They are less dependent on the macroeconomic situation, since they are primarily oriented to the domestic market, however, the small scale of production, the relatively small profit and the low level of capital concentration do not allow them acquiring enough innovative developments to become a key player in the domestic market of ITproducts and services.

Thus, within the framework of the global trend towards the fastest possible reorientation of the agrofood complex to the innovative path of development, the functions of information and consulting services change significantly.

Providing agricultural producers access to the computing resources of the Ministry of Agriculture of the Russian Federation, platforms for the development, deployment and support of digital applications, distributing the necessary software and providing training for specialists in working with the Internet of things and with big data analysis technologies, information and consulting services can become a platform for testing the best foreign practices on the use of ICT in agriculture, to contribute to their nature transfer and adaptation to specific Russian conditions.

\section{Discussion}

In accordance with the informatization plan of the Ministry of Agriculture of the Russian Federation, an online resource was launched in 2016, which was designed to significantly facilitate the work of the federal agricultural advisory system. It combines three technological platforms: information, communication and consulting. The information platform is a database on innovation, technology, business; statistical materials include regularly updated industry directories; technological solutions (tools for collecting and processing information, contact center solutions integrated with CRM (Customer Relationship 
Management) solution. The communication platform provides the opportunity for interaction between the specialists of the agro-industrial information and consulting service system and the industry community. The consulting platform is an integrated web-solution for the provision of a wide range of paid consulting services.

Since modern technologies have transferred part of the functions of the agro-industrial information and consulting services to the Internet, the creation of a centralized database allows, on the one hand, to summarize information gathered from sealed sources on the real state of affairs in the agro-industrial complex over a long period of time.

On the other hand, it gives an opportunity to focus the activities of professional consultants on the implementation of individual orders requiring special field studies. Most of IT start-ups generally avoid using statistically controlled field trials using "fast" data collection and analysis methods to enter the market as quickly as possible. However, their potential customers cannot afford to make a mistake in introducing the new technology. That is why the organization of the demonstration sites by informational and consulting services and the holding of thematic seminars are becoming more and more popular not only among agricultural producers, but also in commercial business structures.

In addition to supporting a centralized database, the functions of the new generation of information and consulting services should also include software distribution. This service can be organized through the network access of all serviced ICS organizations to the public "cloud" of data storage. In addition to software (SaaS - Software as a Service), the "cloud" model provides opportunities for the deployment of service for mobile applications (PaaS - Platform as a Service), and also includes IaaS (Infrastructure as a Service), which allows users exploiting complete set of computing resources to organize their own database [15].

In the future, the creation of a single data center, filling the gaps in the flow of information about the current parameters of each rural infrastructure object and its environment, the formation of uninterrupted communication channels between organizations with a similar profile of activity can be used in the development of artificial intelligence algorithms in the agricultural industry. However, in our opinion, the problem of the influence of technical innovations on the efficiency and quality of agricultural production should be approached more carefully, since too many informal factors exert pressure on it. For all its merits, digital technology is just a tool, and only a person is able to saturate IT with content that more closely matches his needs, goals and objectives.

Agriculture is becoming a sector with a very intensive data flow. Information comes from "field" sensors, meteorological stations, drones, satellites, external systems, etc. On the one hand, robotization and automation of workflows will gradually replace traditional agricultural professions, and on the other hand, they will be a source of new vacancies for programmers, service operators and developers of interaction protocols in Internet of things, etc. [16].

The growing level of technological equipment of modern production complexes, as well as the increasingly high expectations that the digital economy places on them, require not only the retraining of agricultural workers in new high-margin segments (organic farming, the production of specific non-mass types of agricultural products), but also more advanced training on non-agricultural specialties. To eliminate these contradictions and resolve potential crisis situations, the intermediary function of finding partners for IT outsourcing in the agricultural sector should be assigned to information and consulting services. When addressing clients, they can recommend both their own personnel and external specialists, using crowdsourcing technologies, as the most progressive form of consulting activities organizing [17].

Among other things, the activity of information and consulting services improves the institutional structure of agro-food systems, as well as the models of cooperation of its subjects. According to international experience, integration into the production of a package of technologies developed and tested in industries related to the agricultural sector provokes qualitative changes at all stages of agricultural production, contributing to the reduction ofproduction cost and tothe acceleration of the process of its implementation.

Having estimated the volume and structure of demand, the agricultural producer independently contacts the final consumer, reducing the number of links in the value chain, whichaffects the price level of basic food products. The exclusion of wholesale and retail margins and the transition to direct supply of products will cause a significant blow to the shadow agricultural market.The use of electronic trading floors with their transparent settlement schemes to consolidate the contractual relations will create the prerequisites for increasing the volume of lending to the industry and significantly improve its attractiveness for private capital investment.

\section{Conclusion}

In accordance with the Decree of the President of the Russian Federation of May 7, 2018 "On National Goals and Strategic Tasks of the Development of the Russian Federation for the Period until 2024", the country's agrofood complex in the very near future may become one of the leading sectors of the national digital economy. However, at the present stage of development, the domestic segment of the high-tech market, (agroIoT, Big Data, GIS / Spatial Analytics), has still not reached the global level in almost all respects.

Synchronization of the chain of introduction of all newly created or improved technologies in agricultural production requires not only an increase in government support and an increase in domestic expenditures on scientific research, but also a convergence of the subject area of research with the goals and objectives facing the real sector of the economy. 
Information and advisory services are still one of the few connecting links between production and science. It is ICS specialists who work directly with agricultural producers, providing them with practical assistance in mastering advanced production experience and forming a package of orders for conducting the most popular applied research.

In response to the challenges of the time, the further expansion of the functions of regional ICS services may be related to the popularization of methods of precision and organic farming, to the training of users in technologies for working with big data, cartographic materials of spatial sensing and geo-analytics products, as well as to the provision of marketing services for the selection of promising options for technical and technological support of production etc.

Moreover, the national agricultural consulting service plays a significant role in solving the social problems of the village, taking part in the development and implementation of programs for the sustainable development of rural areas, improving the quality of the population life by increasing the number of people employed in the production of information products and services.

Thus, from our point of view, the system of information and consulting support for agricultural producers can become one of the key elements of the future national digital platform for the country's agrofood complex. By synchronizing all stages of the production cycle, uniting producers and consumers of agricultural products, expanding the scope of scientific agricultural research, it forms the natural vector for building a balanced ecosystem of the agro-food complex. It is a system that takes into account not only technological processes of turn from a traditional to an innovatively oriented production form, but also the impact of modern technology on production efficiency potential at the pre-competitive (pre-commercial) stages of implementation.

\section{References}

1. J. Ingram, Agriculture and Human Values 25(3), 405-418 (2008)

2. R. Nettle, L. Klerkx, G. Faure, A. Koutsouris, The J. of Agricult. Ed. and Extension 23(3), 189-195 (2017)
3. G. Faure, Y. Desjeux, P. Gasselin, J. of Agricult. Ed. and Extension 18(5), 461-492 (2012)

4. G. Demishkevich, I. Sandu, Organizational and economic aspects of the development of innovation and consulting activities in the agricultural sector of Russia (2013)

5. R. Ramos-Sandoval, J. García-Alvarez-Coque, F. Mas-Verdú, Spanish J. of Agricult. Res. 14, 106 (2017)

6. C. Laurent, M. Cerf, P. Labarthe, The J. of Agricult. Ed. and Extension 12, 5-16 (2006)

7. L.-A. Sutherland, L. Madureira, V. Dirimanova, M. Bogusz, J. Kania, Land Use Policy 63, 428-439 (2017)

8. R. Birner, K. Davis, J. Pender, E. Nkonya, P. Anandajayasekeram, The J. of Agricult. Ed. and Extension 15(4), 341-355 (2009)

9. R. Nettle, A. Crawford, P. Brightlingb, J. of rural studies 58, 20-27 (2018)

10. N. Röling, M.A.E. Wagemakers (Eds.) Facilitating Sustainable Agriculture: Participatory Learning and Adaptive Management in Times of Environmental Uncertainty (Cambridge University Press, 1998)

11. University of Arkansas System, Division of Agriculture, Cooperative Extension Service, Retrieved from: https://www.uaex.edu/default.aspx.

12. Final Report Summary - PRO AKIS (Prospects for Farmers' Support: Advisory Services in European AKIS), Retrieved from: https://cordis.europa.eu/ project /rcn/ 105025/reporting/en

13. Evaluation of the Implementation of the Farm Advisory System, Retrieved from: https://ec.europa. eu/agriculture/evaluation/market-and-incomereports/2009-fas_en.

14. M. Osovin, M. Kadomtseva, Sci. Review: theory and pract. 4, 481-492 (2019)

15. The European Cloud initiative, Retrieved from: https://ec.europa.eu/digital-smgle-market/en/\%20 european-cloud-initiative.

16. S. Bylina, M. Kadomtseva, M. Osovin, Informatization of the agri-food complex and rural territories of Russia: opportunities and limitations (2018)

17. I. Sandu, V. Savenko, K. Sokolov, Fund. and applied res. of the cooperat. sector of the econ. 6 , 78-80 (2017) 